\title{
Cytopathology of \\ Canine Mammary Gland Affections
}

\author{
Shivani Sangha and Amarjit Singh \\ Additional information is available at the end of the chapter
}

http://dx.doi.org/10.5772/52437

\section{Introduction}

Mammary gland of dogs is the most common site for development of various neoplastic and non-neoplastic affections like tumors, mastitis, steatitis, galactostasis, galactorrhea, agalactia etc. It has been postulated that inflammatory and non proliferative breast diseases do not increase risk of cancer [1]. However, proliferative breast diseases with or without atypia confers mild and moderate risk respectively, whereas carcinoma in situ is associated with substantial risk of life if left untreated [2].The carcinomas often have a poor prognosis due to high rate of local recurrence as well as metastasis, necessitating surgery in some cases adjuvant to chemotherapy [3].The canine mammary tumor (CMT) account for between 25 to 50 percent of all the tumors occurring in the canines [4-6] and are only second to skin tumors [7]. Considering the rate of occurrence of mammary tumors among various species, breast cancer is most frequent in women (32\%), the highly occurring neoplasia (52\%) in bitches and ranks third most common neoplasia $(17 \%)$ in queens after lymphohaemopoietic and skin tumors [8-10]. Keeping in view, the high rate of occurrence, rapid onset of growth, and poor survival statistics of the patients, a quick and early diagnosis of mammary tumor is required.

Today, the worldwide tendency is to look for quick and inexpensive method of tumor diagnosis as the routinely used histological method requires invasive sampling and long hours for processing of the tissue samples. Such a quick, inexpensive, less painful and easily repeatable technique is cytology. It refers to microscopic evaluation of cells which have either naturally exfoliated or has been artificially removed from the body or tissue mass. The technique was first used in the United States by Guthrie in 1921 [11]. The technique requires minimal of sophisticated instruments and is relatively non-invasive technique that obviates the need of open biopsy. Furthermore, implantation of cancer cells after this technique is 
very rare [12]. Diagnostic cytology has recently been employed for diagnosis of some of the tumors in the veterinary medicine [13-15]. When applied to mammary gland tumors, the method showed low sensitivity and specificity $[13,16,17]$.The reasons have been assumed to be heterogeneous composition of mammary tumors [18, 19]. More recently, valuable additional information with improved diagnostic accuracy has been provided by cytological features of fine needle aspirates or from imprints of tissue sections [20, 21]. Both palpable (solid or cystic) or non palpable benign or malignant mammary gland lesions can be diagnosed through this technique. In some studies, combination of cytology, radiology and clinical assessments has resulted in accurate diagnosis in $99 \%$ of cases [22]. Thus, this chapter focus on application of various techniques in evaluating cytological samples from affected mammary gland of canine and feasibility of cytology in differentiating benign and malignant neoplastic lesions.

\section{Techniques of sample collection for cytology of mammary gland}

\subsection{Solid tissue cytology}

\subsubsection{Fine needle Cytology}

Fine needle aspirates are obtained with $10-20 \mathrm{ml}$ disposable syringe bearing 21-25 gauge needle. The softer the tissue, the smaller the needle and syringe used whereas firm tissues like fibroadenomas require larger syringe to maintain adequate pressure [23]. Generally, a $10 \mathrm{ml}$ syringe yield adequate cytological sample from mammary gland of dogs. The mass is located clinically and stabilized in position. The skin over the puncture site is cleaned with alcohol or spirit and the samples are collected using aspiration or non-aspiration procedure.

Aspiration procedure

After cleaning the mass with some antiseptic solution, the needle with syringe attached is introduced into the centre of mass. Strong negative pressure is applied by withdrawing the plunger to about $3 / 4$ th of the volume of syringe. The needle is moved through the mass three or four times in different directions. Still with the needle in the mass, suction is slowly released. The needle is then removed from the mass and the syringe from the needle. The syringe is then filled with little air and then reconnected to the needle. Finally, the contents of the needle are blown on to one or more clean dry slides, which are rapidly air dried.

\section{Non-aspiration procedure (Capillary technique/ Stab technique)}

This technique is similar to the standard fine needle aspiration technique, except no negative pressure is applied during collection. Here the plunger of syringe is filled with air before the collection attempt so as to allow rapid expulsion contents onto a glass slide.

Caution: Usually in both the cases, the aspirate may not be visible in the syringe. However, when the air pressure is applied to syringe for expulsion of contents on the slide, the needle will contain sufficient tissue for cytological smear preparation. 


\subsubsection{Tissue imprints or Impression smears}

Tissue imprints can be obtained by pressing the glass slide over the lesion from live animal or from the surface of the tissue excised during surgery. Do this several times, to have multiple impressions over one slide. Samples collected through touch impression contain tissue cells, superficial inflammatory cells and greater microbial contamination as compared to aspirates or swabs.

To minimize microbial or cellular contamination, clean the area of the lesion with cotton swab moistened with saline solution. Do not use water to prevent osmosis induced cell rupture. In case, imprints are to be obtained from the tissue excised during surgery, the surface of excised tissue is cut to get a fresh surface for impression smear. Next, the excess blood and tissue fluid is swabbed/ dabbed from the area to be imprinted by blotting paper, and the surface of lesion is pressed hard against the clean glass slide. No further smearing of the material is done to avoid cellular distortion and the slides are simply air dried.

\subsection{Fluid Cytology}

In case if fluid is filled in the syringe during fine needle aspiration, collect it in a sterile tube. Quickly, make few smears from the fluid. To avoid coagulation, keep a portion of specimen in some anticoagulant (preferably EDTA) containing vial and other portion of sample in sterile capped test tube (for the purpose of microbial culture, if required, as anticoagulant prevents microbial growth).

\subsubsection{Tissue imprints or Touch Impression smears}

Teat of affected mammary gland occasionally shows fluid on squeezing. For making touch impressions, teat orifice is cleaned with spirit swab and then pressed hard against the clean dry glass slide to get the touch impression. If fluid is found enough, a smear can also be drawn.

\subsubsection{Swabs}

These are collected in case of purulent lesions or fistulous tracts. Before collection of sample, the lesion should be cleaned with moist and sterile cotton. The swab is directly introduced into the lesion and then gently rolled on the glass slide to make the smear. Dry the smears in air. Do not rub the swab over the slide as it will result in distortion of cell size and shape thus leading to misdiagnosis.

\section{Choice of technique for sample collection}

Choice of technique for collection of cytological sample depends on nature of lesion as mention below: 
Solid lesions: Fine needle aspirates are preferred for obtaining samples from solid lesions. Aspiration procedure is commonly used, however, Non-aspiration procedure is recommended for highly vascular lesions. Touch impressions can also be made in addition to aspirates.

Ulcerative superficial lesions: Impression smears should be made both before and after cleaning the ulcerated surface.

Teat fluids and secretions: Touch impressions or swabs are useful.

\section{Preparation of Slides}

A minimum of four to six slides from multiple sites within the lesion are made using following techniques

\subsection{Slide-over-slide smears (Squash Preps)}

The technique is useful in case aspirated material is thick. The material collected from the fine needle cytology procedure is expelled near one end ( 0.5 inch) of a clean glass slide ("sample" slide). A second glass slide ("spreader" slide) is placed on top of and perpendicular to the slide containing the sample. The spreader slide is then lightly drawn out across the length of bottom slide, spreading the sample. No downward pressure is applied to the spreader slide while making the smear as this usually result in rupturing of cells. Squash preps result on fine spreading of the cells and yield better cytological diagnosis in case of samples containing flecks of particulate matter.

\subsection{Blood smear technique}

To prepare the smear by blood smear technique, a small drop of sample is placed on the glass slide approximately 0.5 inch from the end. Another slide is moved over it an angle of $30^{\circ}-40^{\circ}$ until it contacted the drop. When the sample fluid fills the crease between the slides, gently slide the second slide forward until the sample fluid drains away from the second slide. This results in a cytological smear with feathered edge.

\subsection{Starfish preparation}

Here the aspirate is dragged peripherally in several directions with the point of a syringe needle, producing a starfish shape. This technique tends not to damage fragile cells but allows a thick layer of tissue fluid to remain around the cells.

\subsection{Sediment smear}

For making sediment smear, centrifugation of the fluid is done for 5 minute at $165-360 \mathrm{G}$ to concentrate the cells. A drop from this cellular concentrate is taken to make the smear just like blood smear. Further analysis of cellular concentrate for the physical (specific gravity) and chemical properties (total protein, calcium etc) can be helpful to determine the pathogenesis of the disease. 


\subsection{Combination technique}

Here, one drop of the aspirate is taken on the slide (specimen slide). A spreader slide is kept on the one third of the aspirate and squash prep is made. Next, a slide tilted at angle of 30 degree is placed on the end opposite to squash prep portion. As this slide comes in to contact with one third of the aspirate, the slide is moved forward and slid like making a blood smear. Now, the smear is having one third area spreaded like blood smear, middle one concentrated and untouched and the other one-third area spreaded by squash prep method.

\subsection{Line smear concentration technique}

When the aspirated fluid contains few cells which do not sediment upon centrifugation, line smear technique is useful. Here, a drop of fluid is taken at one end of the clean slide. A spreader slide is used to spread the drop on previous slide in a manner similar to blood smear technique except that the spreader slide is raised directly upwards after covering three fourth of the smear. This results in a smear with line containing higher concentration of cells than the rest of slide.

\section{Precautions while slide preparation for cytology}

One should proceed to prepare the slide for cytological examination as soon as possible after collection of the specimen. This will prevent the sample from clotting or drying out on the slide before preparation of the smear. Another caution to be kept in mind is always use tip of the needle to spread the sample to avoid distortion in cellular shape. Also, avoid making too thick smears so that blood or other exfoliated cells do not dominate the main cell type by controlling the amount of sample being expelled from the syringe. While making squash smears, gently pull the two slides apart as too much pressure will cause cellular disruption. Always prepare at least four to five smears from one specimen in order to increase diagnostic sensitivity and specificity. Frosted or colored edged slides are preferred for cytological studies as labeling of these slides help in permanent marking and easy identification of upward side of slide containing usually colorless sample and hence prevents wipe off sample in error during staining procedure. During cytological examination of fluids, always make few smears immediately after collection of fluids as quality of cells from sample kept in EDTA containing vials is not as good as fresh sample.

\section{Staining of Cytologic Smears}

Cytologic smears can be stained with Papanicolaou stains and it's derivatives like Sano's trichome or Romanowsky type stains like Wright stain, Leishman stain, Diff- quick, Dipstat etc.

\subsection{Papanicolaou stains}

These stains use wet smears (i.e. the smear needs to be fixed before staining) and provide excellent nuclear and cell structural details but do not stain the cytoplasm and many organisms 
well. The staining with these stains involves multiple steps and thus requires considerable time also. These factors restrict the use of papanicolaou stains in the veterinary cytology.

\subsection{Romanowsky type stains}

Romanowsky type stains are the preferred stains for the cytological studies in veterinary practice. These are permanent stains and use air dried smears. Different stains like Wright stain, Leishman stain, Giemsa stain etc. come under this category and staining is done as per their standard protocols. Wright-Leishman combination can also be used which is made by mixing 3 parts of Wright stain with 1 part of Leishman stain [24]. Slides are stained in similar manner as for the standard Wright's technique except that the staining time is extended to 6-8 minutes. When there is a confusion to decide exact time limit between time range given for staining, keep in mind that thicker the smear or more the protein content in the aspirate, more is the time required for the stain [23]. So, select for higher value from the time range in case of thicker aspirates.

Romanowsky stains excellently stain the cytoplasm and the other micro-organisms present in the smear but due to smudging effect of these stains on the nucleus, nuclear and nucleolar details are not much appreciable. However, the detail is sufficient enough for differentiating neoplastic lesions from inflammatory lesions. These stains dissolve cellular lipids leaving vacuolated areas in the smear after staining. To overcome this problem, new methylene blue (NMB) stain can be used in combination to Romanowsky stains which outlines the lipid droplets and the fungi. Also, staining with New methylene blue stain is useful in diagnosis of blood contaminated samples as NMB do not stain RBC hemoglobin. As this stain is wet mount, non-permanent stain, the smears can be counter stained with Wright or Giemsa stain to get permanently stained smears.

To conclude, being quick, inexpensive, easily available and readily staining the cytoplasm and most of the organisms in the cytological smears, Romanowsky stains remain first choice of the cytologists on veterinary side. These stains help to screen inflammatory lesions from non-inflammatory mammary gland lesions, to diagnose causative agent in case of inflammatory lesions like streptococcal mastitis or tuberculosis and further assessing the malignancy potential of the mammary tumors. In particular cases, if further nuclear detailing is required, papanicolaou stains can be used.

\section{Microscopic examination of slides}

\subsection{Cell count}

The issue of specimen adequacy in breast FNAs remains controversial and has been addressed by several authors. It is advocated that a minimum number of epithelial cells be required for diagnosis and the samples containing fewer than the specified minimum be reported as non-diagnostic. Interpretations based on inadequately cellular specimen may not contain a representative sample of the lesion, giving a false impression of normalcy, or, even worse, may result in a false impression of a neoplasia that is not really present [23]. The 
published recommendation for the minimum number of cells in the cytological smear is of at least six clusters of cells with a minimum of 5-10 cells per group [25, 26].

\subsection{Type of cells}

After getting an idea for sufficient number of well stained cells in the cytologic smear from mammary gland aspirate, observe for the cell type to judge whether the lesion is inflammatory or neoplastic in nature.

\subsubsection{Inflammatory cells}

Neutrophils, macrophages, lymphocytes, eosinophils and epitheliod cells are commonly encountered inflammatory cells from the aspirates of mammary lesions. Neutrophils are multinucleated and are usually characterized by mild nuclear alterations like nuclear swelling, chromatin hyalinization, foamy cytoplasm etc. to severe degenerative changes like karyorrhexis and karyolysis. Eosinophils dominate during allergic response to some foreign body. The cells like monocytes/macrophages, lymphocytes and epitheloid cells dominate during chronic inflammatory lesions like granulamatous mastitis.

\subsubsection{Non-Inflammatory cells}

\section{Epithelial cells}

These cells are variable in size from small (basal cells) to large with particular feature of cell to cell adhesion. This adhesion causes cells to be present in form of sheets or clumps. Epithelial cells generally contain round to oval nuclei with clear cytoplasmic boundaries.

Mesenchymal cells

These are usually elongated cells with round to rod shaped nuclei and the cytoplasm tapering in one or more directions. Characteristically, mesenchymal cells have indistinct cytoplasmic boundaries that blend with the background. Due to cohesive nature of connective tissue from which the mesenchymal cells originate, cellular smears are sparsely populated.

Note: Mixture of inflammatory and non-inflammatory cells suggest neoplastic lesion with secondary inflammation.

\subsection{On the basis of observing the cell type, the mammary gland lesions can be broadly classified as}

\subsubsection{Inflammatory lesions}

Inflammatory breast aspirate shows low cellularity with epithelial cells arranged in clusters and small groups with the presence of myo-epithelial cells. Cytological atypia and nuclear changes are minimal $[27,28]$.The Inflammatory lesions can be cytologically classified as: 


\section{Acute Inflammatory lesions}

Mainly neutrophils dominate the smear (>90\%) and usually show degenerative changes like nuclear swelling, foamy cytoplasm etc. Extracellular, eosinophilic material is usually present in considerable amount. For example: Purulent mastitis, udder abscess etc.

\section{Mixed (Chronic-Active) Inflammatory lesions}

It is an intermediate stage with cellular smears showing mixture of neutrophils (50-70\%) and mononuclear cells like monocytes and lymphocytes. Macrophages and epitheloid cells can also be observed. The cellular smears taken from the animals suffering from affections like fat necrosis, organized hematoma, steatis etc. also exhibit mixed inflammatory lesions.

\section{Chronic Inflammatory lesions}

This category of lesions present cellular smears dominated by mononuclear inflammatory cells like lymphocytes, macrophages, multinucleated giant cells and or numerous epithelial macrophages. For example: Granulamatous mastitis, tuberculous mastitis.

\subsubsection{Non-Inflammatory lesions}

\subsubsection{Hyperplastic / Dysplastic lesions}

Hyperplasia and dysplasia are the proliferative lesions that make normal tissue resembles neoplastic cells. Like aspirates from neoplastic lesions, aspirates from epithelial or mesenchymal hyperplastic lesions do not present good nuclear criteria of malignancy like variable nuclear to cytoplasmic ratio, macronucleoli and abnormal chromatin patterns. Rather, the hyperplastic cells present a constant nuclear to cytoplasmic ratio as they are proliferating under controlled mechanism. Dysplastic and hyperplastic lesions include lobular hyperplasia, adenosis etc.

Note: A mixture of inflammatory and tissue cells suggest neoplasia with secondary inflammation or inflammation with secondary tissue cell dysplasia.

\subsubsection{Neoplastic lesions}

The type (benign or malignant), grade and tissue of origin of various neoplastic lesions of mammary gland can be diagnosed from cytological smear by studying the nuclear and cytoplasmic details and chromatin patterns as described in section 7.4.

\subsection{Cytological and nuclear criteria of malignancy: Mammary gland tumors}

On basis of nuclear and cytoplasmic details, cellular smears of mammary gland tumors can be classified in the following manner:

a. On the basis of behavior of tumor as benign or malignant [29].

b. On the basis of tissue of origin as epithelial, mesenchymal or mixed type [30].

c. On the basis of severity of tumor as grade I, II or III [31]. 


\subsubsection{On the basis of behavior of tumor: Benign or malignant}

Tumors can be classified as benign or malignant according to following criteria [29]:

\begin{tabular}{|c|c|}
\hline \multicolumn{2}{|l|}{ General criteria } \\
\hline 1. Anisocytosis & Variations in the cells sizes \\
\hline 2. Pleomorphism & Variations in the shapes of cells of the same type \\
\hline 3. Hypercellularity & Increase in the number of exfoliated cells \\
\hline \multicolumn{2}{|l|}{ Nuclear criteria } \\
\hline 1. Macrokaryosis & Increase in size of nuclei \\
\hline 2. Anisokaryosis & Variations in size of nuclei \\
\hline 3. Multinucleation & Increase in the number of nuclei \\
\hline 4. Nuclear / Cytoplasm ratio & Increased \\
\hline 5. Nuclear molding & Deformation of the nuclei \\
\hline 6. Mitotic figures & Increased and abnormal \\
\hline 7. Chromatin pattern & Coarse pattern \\
\hline 8.Macronucleoli & Increase in the size of the nucleoli. \\
\hline 9. Angular nucleoli & Presence of angular nucleoli \\
\hline 10. Anisonucleosis & Variation in size of nucleoli \\
\hline
\end{tabular}

Table 1. Classification of mammary tumors according to behavior of tumor (Benign or Malignant)

If three or more of the below mentioned tumor criteria are present, tumor is of malignant type otherwise benign type.

Various terms are used to assess abnormal chromatin pattern in the nucleus like strippled, reticular or lacy, coarse, clumped or smudged chromatin. The fine smooth chromatin shows uniform pattern of thin chromatin strands with fine borders. Strippled pattern refers to smooth pattern of chromatin with small aggregates of chromatin dispersed in whole of the nucleus. When the chromatin strands appear thicker than normal, the term reticular or lacy chromatin is used. When the chromatin strands become very thick, giving ropy or chordlike appearance, coarse chromatin pattern is indicated. When large aggregates of reticular or coarse chromatin are dispersed throughout the nucleus, the clumped chromatin pattern is visible. Further, if the boundaries of chromatin strands or clusters are not very discrete and become vague, it leads to smudged pattern of the chromatin. 


\subsubsection{On the basis of tissue of origin (Histogenic classification)}

According to type of tissue from which tumor originated, the tumors can be classified as epithelial, mesenchymal or mixed type of tumor [30].

\subsubsection{Epithelial tumors}

These are epithelial in origin and often exfoliate in clumps or sheets. Cytologically, the smears contain clusters, clumps or sheets of cells with round to oval nuclei and clear cytoplasmic boundaries (Fig.1). Adenomas, adenocarcinomas and mixed mammary adenocarcinoma are grouped as epithelial tumors. In case of adenoma or adenocarcinoma the cells may get arranged in acinar or ductular pattern with central lumen. In case of papillary or cystic adenomas, cytoplasm may appear distended by secretory product.

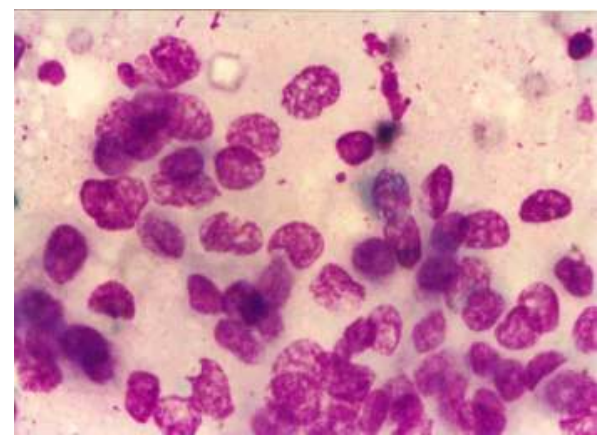

Figure 1. Epithelial tumor: Fine needle aspirate smear consist of cells situated in separate groups with round to oval nuclei and lined by clear cytoplasmic boundaries, Wright-Leihman x 750 .

\subsubsection{Mesenchymal Tumors}

These originate from connective tissue. In contrast to epithelial tumors, mesenchymal tumors do not exfoliate regularly and are found as individually settled polygonal/elliptical/stellate or spindle shaped cells with poorly defined cell membrane (Fig.2). Lipoma and liposarcoma are classified under this category.

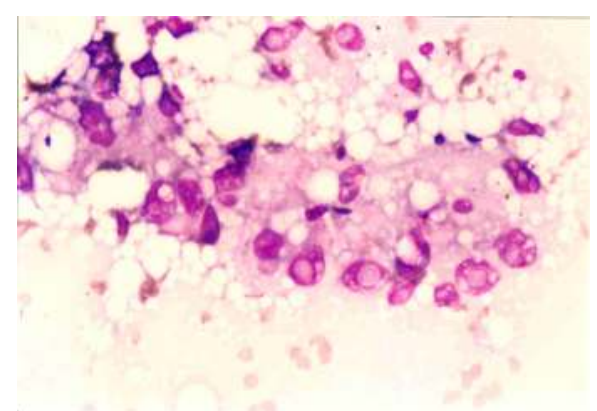

Figure 2. Mesenchymal tumor: Consist of individually settled pleomorphic cells with scarce cytoplasm and poorly defined cell membrane, Wright- Leishman x 150 . 


\subsubsection{Mixed type of Tumors}

Mixed type of tumors reveal cellular elements of both epithelial and mesenchymal type (Fig.3). Thus, clusters of cells with round to oval nuclei and clear cytoplasmic boundaries as well as individually settled polygonal/elliptical/stellate or spindle shaped cells with poorly defined cell membrane are found in the cellular smear. Mixed mammary adenoma and mixed mammary adenocarcinoma are included in this group.

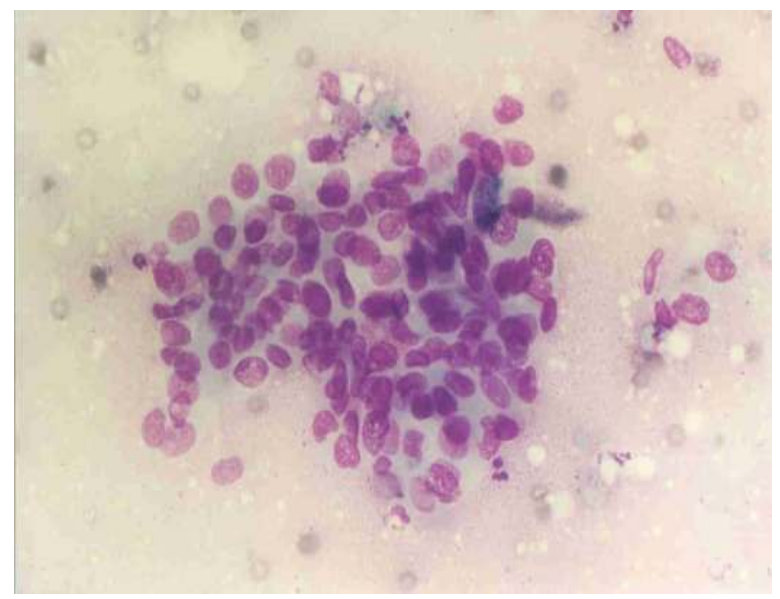

Figure 3. Mixed tumor: Touch impression composed of oval stellate cells located in clusters as well as individually settled in the smear. Cells are hyperchromatic, contain intracytoplasmic vacuoles and have increased nuclear to cytoplasmic ratio, Wright-Leishman $x 300$.

\begin{tabular}{|l|l|}
\hline Types of tumor & Characteristics \\
\hline 1. Epithelial & $\begin{array}{l}\text { Cells in separate groups or together with clear cytoplasmic } \\
\text { boundaries and round/oval nuclei. }\end{array}$ \\
\hline 2. Mesenchymal & $\begin{array}{l}\text { Individually settled cells mixed with extra cellular matrix, poorly } \\
\text { defined cell membrane scarce cytoplasm, oval/ elliptical nuclei, } \\
\text { polygonal, fusiform/ stellate or elliptical cells. }\end{array}$ \\
\hline 3. Mixed & $\begin{array}{l}\text { Both epithelial and mesenchymal cellular elements in variable } \\
\text { number. }\end{array}$ \\
\hline
\end{tabular}

Table 2. Classification of mammary tumors according to tissue of origin (Histogenic classification)

\subsubsection{On the basis of severity of tumor (Cytoprognostic Classification)}

The smears can be graded into three types in order of increasing severity. A simple numerical system is applied to both topographic and cytology criteria as shown in the table below [31]. 


\begin{tabular}{|c|c|c|}
\hline & Morphology & Score \\
\hline \multirow[t]{3}{*}{ Cells } & Isolated & 3 \\
\hline & In clusters & 0 \\
\hline & Large size & 3 \\
\hline \multirow[t]{5}{*}{ Nuclei } & Anisokaryosis & 2 \\
\hline & Naked & 3 \\
\hline & Budding & 2 \\
\hline & Hypochromasia & 3 \\
\hline & Hyperchromasia & 2 \\
\hline \multirow[t]{2}{*}{ Enlarged Nucleoli } & Red & 3 \\
\hline & Blue & 2 \\
\hline \multirow[t]{2}{*}{ Mitosis } & $>3 /$ slide & 1 \\
\hline & $>6 /$ slide & 3 \\
\hline
\end{tabular}

Table 3. Cytoprognostic classification of mammary gland tumors

Grade is obtained by adding the different scores obtained

Grade I: Score $<5$

Grade II: Score 5-9

Grade III: Score $>10$

When a double malignant cell population is found in same tumor, the most anaplastic cells are taken in to account for scoring purpose.

\section{Diagnostic interpretation of fine needle aspirates (FNAs)}

Fine needle aspirates from the neoplastic lesions often present smears with variety of confusing cell population and it is very difficult to give concise and clear interpretation. Following the Guidelines of the Papanicolaou Society of Cytopathology for Fine-Needle Aspiration Procedure and Reporting, the smears can be interpreted in a very clear and concise manner tabulated below [32]. 


\begin{tabular}{|c|c|}
\hline Interpretation & Characteristics of cellular smear \\
\hline 1. Inadequate / Unsatisfactory & $\begin{array}{l}\text { Acellularity / hypocellularity, poor fixation, poor } \\
\text { staining, poor preparation (crush artifact), excessive } \\
\text { blood, necrosis or debris. }\end{array}$ \\
\hline $\begin{array}{l}\text { 2. Benign } \\
\text { a). Aspirates in which diagnosis } \\
\text { can be given }\end{array}$ & Benign cells with characteristic cytological features. \\
\hline $\begin{array}{l}\text { b). Aspirates in which only a } \\
\text { negative narrative diagnosis is } \\
\text { possible }\end{array}$ & $\begin{array}{l}\text { No malignant cell population is seen in given specimen } \\
\text { but clinician is advised to correlate the lesion with } \\
\text { clinical findings or to do re-sampling from multiple sites } \\
\text { of the lesion. }\end{array}$ \\
\hline 3. Malignant & Smears contain cells diagnostic of malignancy. \\
\hline 4. Suspicious for malignancy & $\begin{array}{l}\text { a). Sample contain few poorly preserved malignant cells } \\
\text { or obscured by blood or inflammatory. } \\
\text { b). Only some features of malignancy are present but } \\
\text { clinical history show indication for malignancy. } \\
\text { c). Cytological criteria of malignancy overlap with } \\
\text { benign lesions. }\end{array}$ \\
\hline 5. Atypical cells present & $\begin{array}{l}\text { Adequate sample containing mostly benign cells but few } \\
\text { atypical cells which are unlikely to be malignant. }\end{array}$ \\
\hline
\end{tabular}

Table 4. Diagnostic Categories of Fine Needle Aspirates

\section{Common misleading artifacts and contaminants in cytological smears}

Stain precipitates, glove powder, keratin bars, talc crystals, air drying artifact, lubricant jelly artifact and formalin fume artifacts usually lead to misinterpretation of cytological slides. Cytology slides should not be even kept near formalin jars as the formalin fumes partially fix the cells of air dried smears and interfere with the staining of slides.

\section{Clinico-cytological observations of mammary gland affections}

\subsection{Mastitis}

In bitches affected with acute mastitis (Fig. 4), cytologic examination of secretions from inflamed mammary glands reveals bacteria and numerous degenerative neutrophils (Fig.5). Samples of milk taken from affected mammary gland of bitches show gel formation during sodium lauryl sulphate reagent test (Fig. 6) and color change of milk sample from yellow to green occur on addition of bromothymol blue reagent to it. Both these tests confirm the presence of high degree of mastitis in affected animals diagnosed cytologically. 


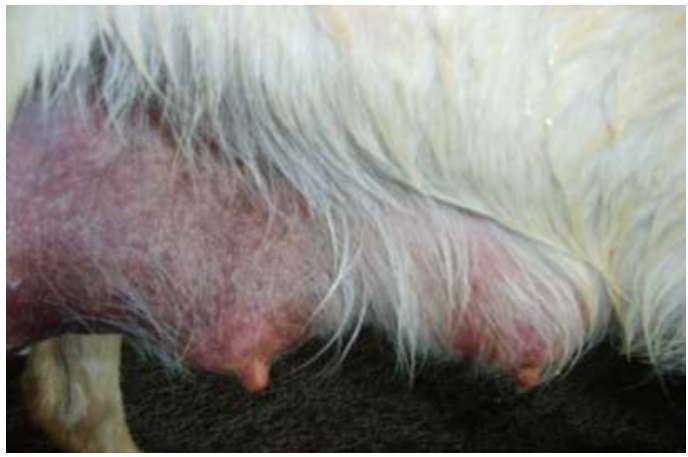

Figure 4. Mastitis: Red, hot, inflamed mammary gland of 4 year old Labrador Retriever bitch.

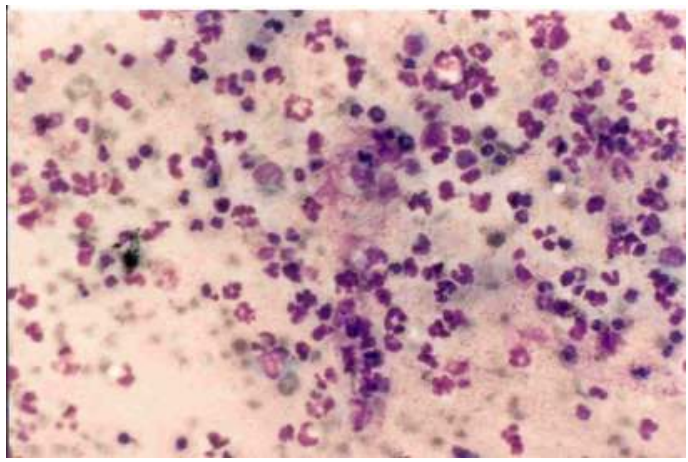

Figure 5. Mastitis: Fine needle aspirate showing numerous degenerative neutrophils and bacteria, Wright-Leishman X 300 .

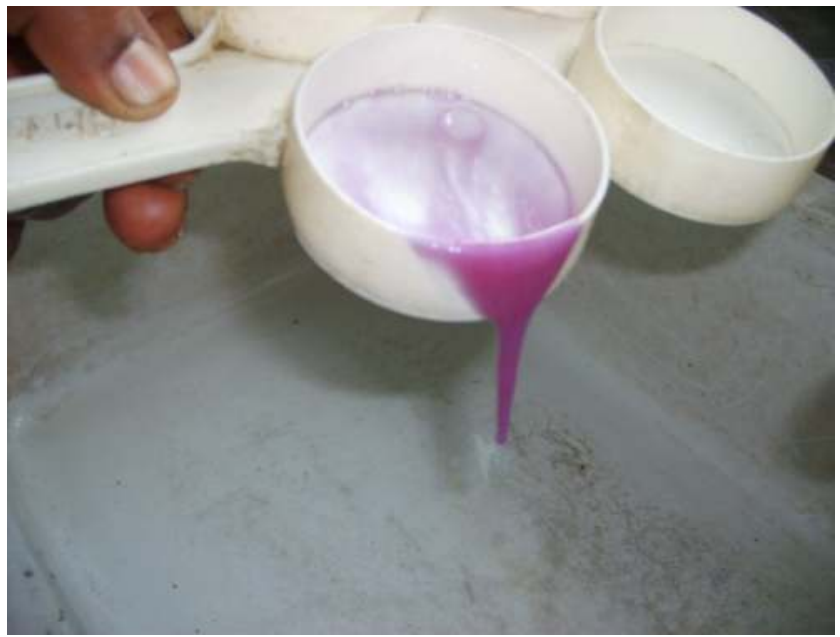

Figure 6. Milk sample from inflamed mammary gland undergoes dense gel formation on addition of sodium lauryl sulphate reagent which confirms mastitis. 


\subsection{Steatitis}

Steatitis is inflammation of subcutaneous adipose tissue. Cytologically, the aspirate reveals inflammatory cells (neutrophils, monocytes) infiltrating the adipose tissue (Fig. 7).

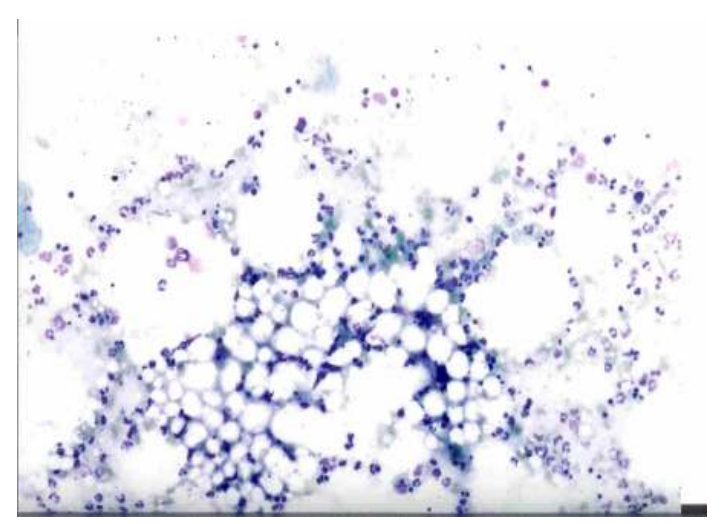

Figure 7. Steatitis: Fine needle aspirate consisting of inflammatory cells infilterating the adipocytes, Wright- Leishman x 150.

\subsection{Lipoma}

Mature lipocytes containing abundant fat usually rupture during aspiration of lipomas and yield oily smears containing free fat with few lipocytes. These smears do not dry in air and the fat get washed off on staining with alcohol based stains leaving behind few lipocytes with clear empty areas. Cytologically, smears reveal single or group of large fat cells containing large volume of pale cytoplasm and outlined by a single thin membrane. The nucleus is small, dense and pushed to periphery of cell (Fig. 8). Stains like Sudan IV, Oil Red O, New Methylene blue may be used to visualize fat cells directly on fresh smears before alcohol fixation.

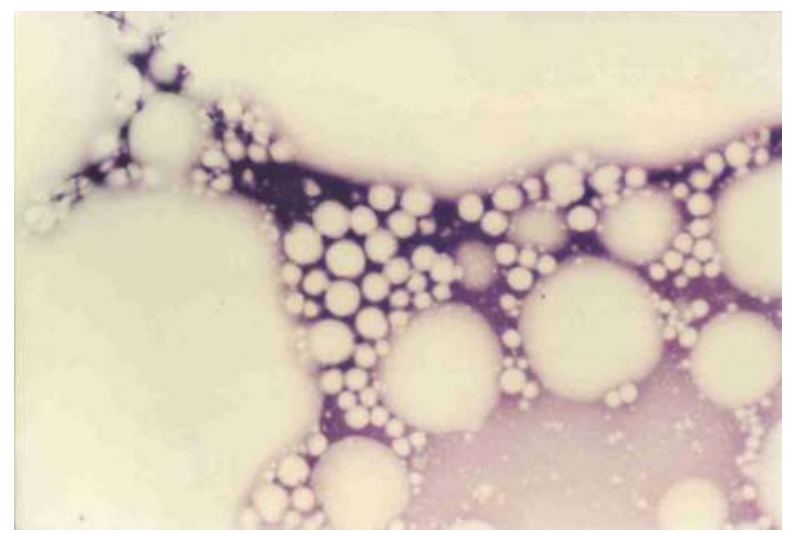

Figure 8. Lipoma: Poorly cellular fine needle aspirate smear with abundant free lipid residue from disrupted adipocytes, Wright x 150 . 


\subsection{Liposarcoma}

In comparison to lipomas, fine needle aspirates of liposarcoma are characterized by abundant lipocytes or lipoblasts, free fat and thus appear greasy. Sometime the smears contain abundant lipoblasts and lipocytes but very little free fat may not give oily appearance. Cytologically, the aspirates are characterized by hypercellularity, pleomorphism, anisokaryosis, cells with vacuolated cytoplasm and nuclei displaced to periphery of cells (Fig.2).Small to large fat vacuoles may be observed in background of smear. In general, the more immature and anaplastic cells have fewer and smaller fat globules. Typically, the lipoblast nucleus is round and variation in nuclear size and multinucleation is seen.

\subsection{Adenocarcinoma}

Adenocarcinomas appear as hard, solitary well encapsulated, round or discoid growths which measure up to $10 \mathrm{~cm}$ in diameter (Fig.9). Cytologically fine needle aspirates are characterized by anisocytosis, macrocytosis, hypercellularity, multinucleation, increased nuclear to cytoplasmic ratio and prominent nucleoli (Fig.10).

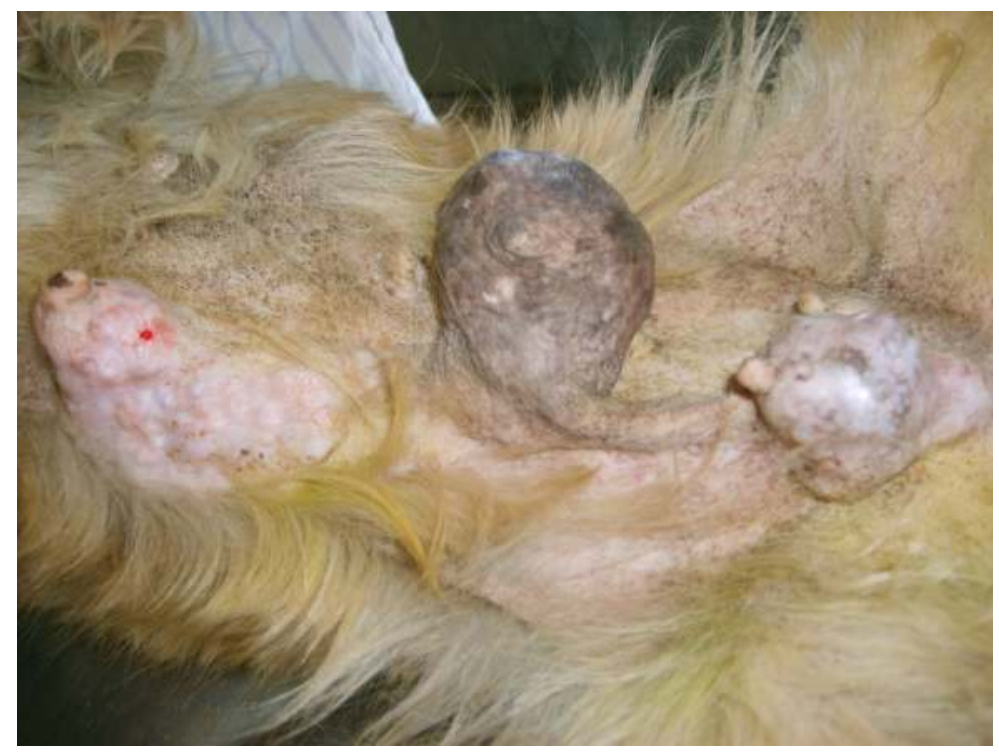

Figure 9. Adenocarcinoma: Three year old Golden Retriever with hard pendulous globate masses involving multiple pair of mammary glands. 


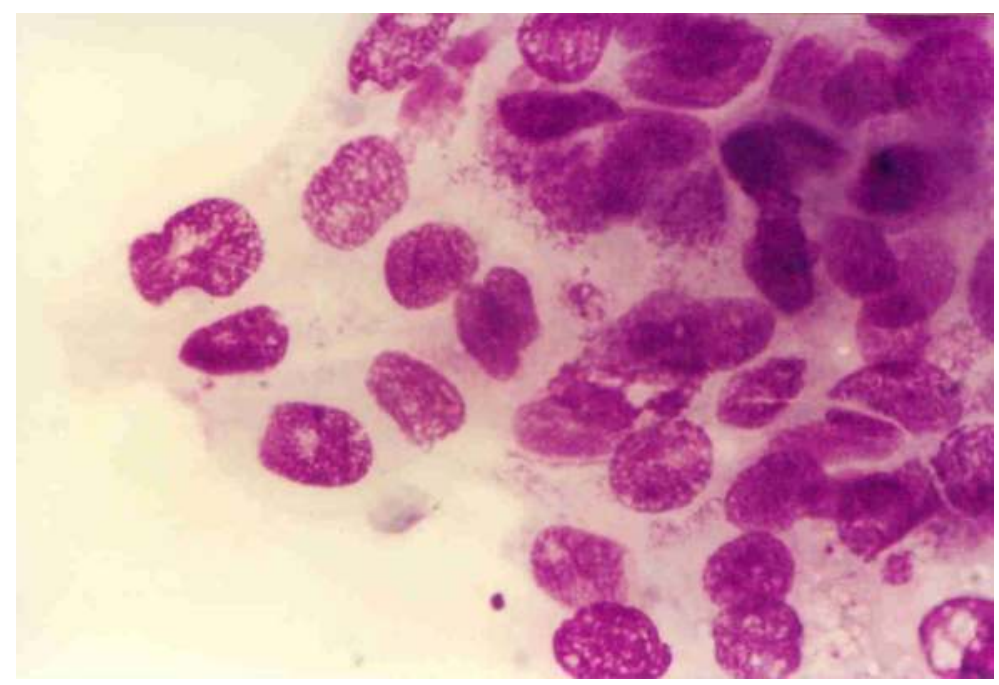

Figure 10. Adenocarcinoma: Fine needle aspirate with hypercellular pleomorphic, large hyperchromatic naked cells with coarse chromatin and prominent nucleoli, Wright $\times 750$.

\subsection{Inflammatory adenocarcinoma}

Fine needle aspirates of inflammatory adenocarcinoma reveal isolated or clusters of hyperchromatic epithelial cells with enlarged nuclei, prominent nucleoli and coarse chromatin. Inflammatory cells like neutrophils and lymphocytes infiltrate the surrounding tissue (Fig.11). Grossly, the growths are about 2 to $10 \mathrm{~cm}$ in diameter, fixed to body wall and vary from soft to hard in consistency.

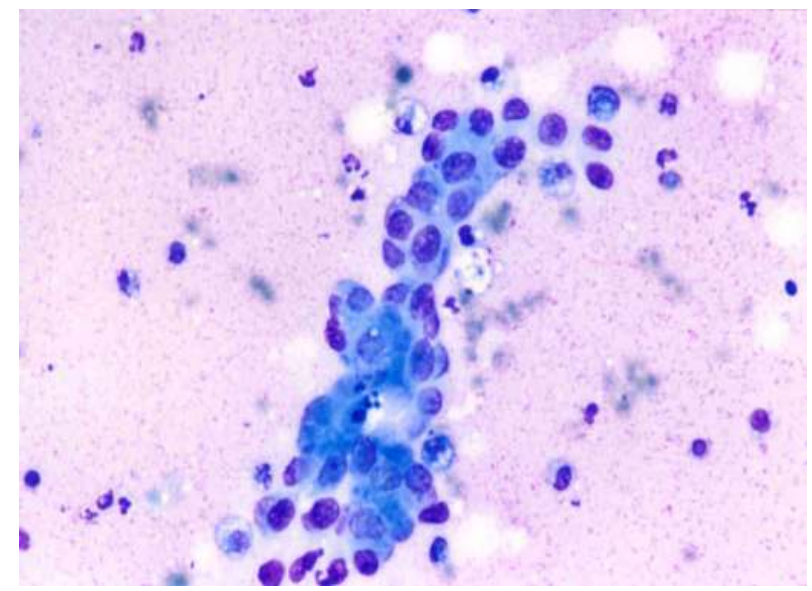

Figure 11. Inflammatory adenocarcinoma: Touch impression consisting of hyperchromatic cells with enlarged nuclei having prominent nucleoli, more basophilic cytoplasm and intracytoplasmic vacuoles. Inflammatory cells infilterate the surrounding area, Wright-Leishman x 150. 


\subsection{Mixed mammary adenoma/adenocarcinoma}

The mixed tumors are usually multiple, occasionally solitary. They appear as small circumscribed nodules of about $2 \mathrm{~cm}$ in diameter and as pendulous, globate masses up to 10 $\mathrm{cm}$ in diameter. Grossly the affected areas are well encapsulated, hard, fibrous, and cartilaginous and may show glistening white lobules of fibrous tissue with multiple cysts filled with straw colored fluid and irregular areas of glandular tissue. In some cases, gritty sound can be observed on excision of the affected tissue. Cytologically, the aspirates contain both epithelial and stromal elements. The smears are hypercellular containing hyperchromatic spindle shaped connective tissue cells (Fig.12) and clusters of epithelial cells as described in adenocarcinomas.

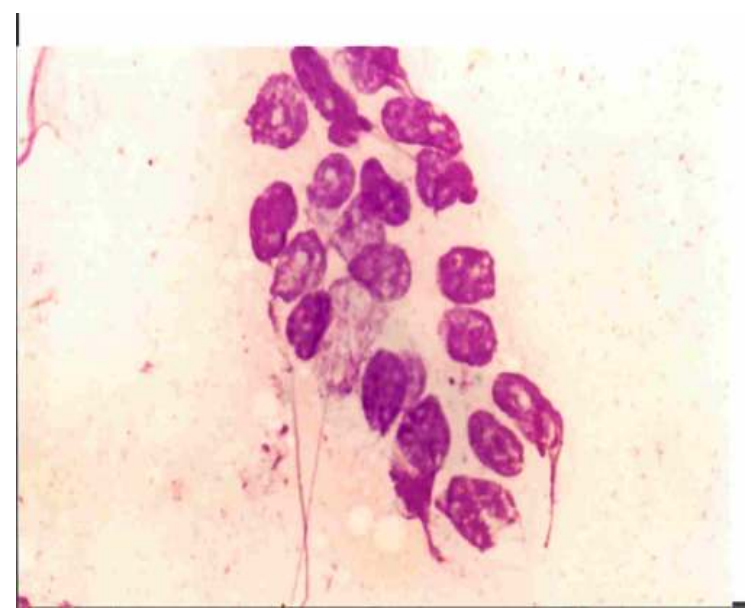

Figure 12. Mixed mammary tumor: Fine need aspirate containing oval to spindle shaped pleomorphic cells, Wright-Leishman $\times 750$.

\subsection{Squamous cell carcinoma}

These are epithelial tumors characterized by variation in cell shape from round to polygonal to tadpole to linear to rectangular. There are large cells with abundant cytoplasm that have retained large functional non-pyknotic nucleus and coarse to marginated chromatin. The nuclei may be encircled by vacuoles or vacuoles may be scattered throughout the cell [23]. Neutrophils are commonly seen in the smear as the carcinoma lesions are usually ulcerated and infected.

\subsection{Adenoma}

Grossly, the growths are hard to soft in consistency varying from 2 to $10 \mathrm{~cm}$ in diameter (Fig. 13). In contrast to adenocarcinomas, fine needle aspirates of adenomas yield clusters of morphologically uniform population of well differentiated cells with little or no pleomorphism (Fig.14). 


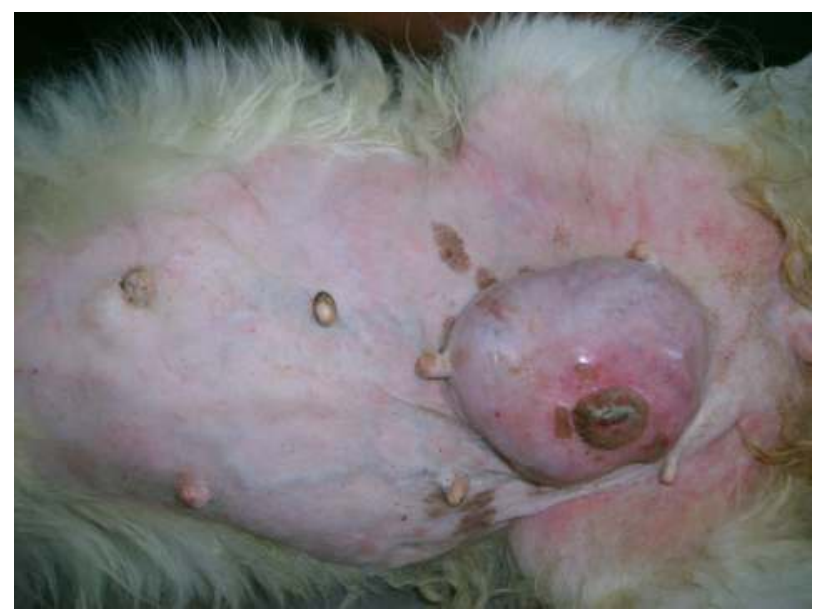

Figure 13. Adenoma: Localized small nodular growth on right inguinal mammary gland of a nine year old female Pomerian dog.

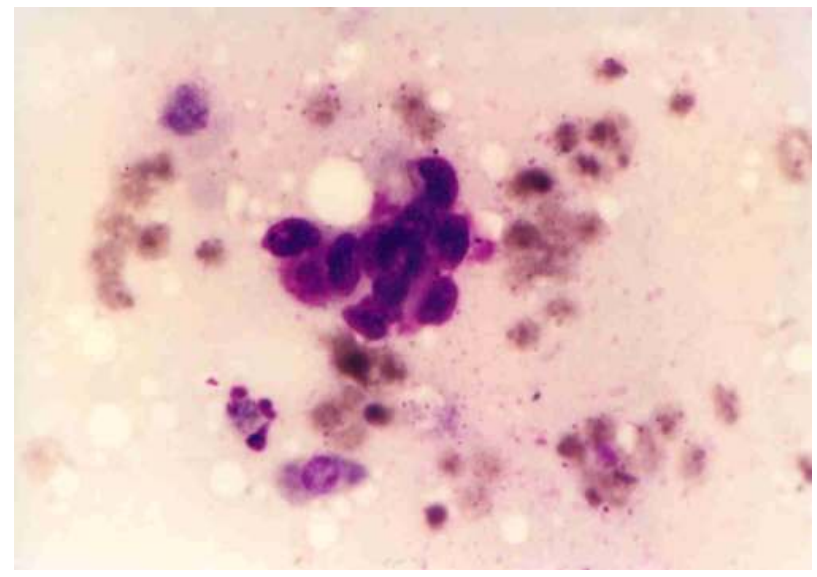

Figure 14. Adenoma: Fine needle aspirate composed of clusters of clusters of cells with highly basophilic cytoplasm, variable shaped nuclei and increased nuclear to cytoplasmic ratio, WrightLeishman $\times 300$.

\subsection{Fibroadenoma}

Fibroadenomas are benign skin lesions and are usually found solitary on the body. Cytologically, the smears are hypercellular with sheets of epithelial cells mixed with fusiform to stellate shaped pleomorphic myoepithelial cells. The nuclear to cytoplasmic ratio is increased, nuclear chromatin is fine to lacy and the cells have tail of cytoplasm that appear to trail away from the nucleus in one or two directions. The added presence of large number of bipolar/naked nuclei in the background of the smear is the reliable cytological feature in favor of fibroadenoma [33]. 


\subsection{Papillomas}

These are benign epithelial growths varying from cauliflower like to papillary projections with thin stalks. Aspiration yields uniform, large, polygonal cells with round to ovoid nuclei having low nuclear to cytoplasmic ratio. The abundant cytoplasm is lightly basophilic and foamy to eosinophilic and granular. Neutrophils may be prominent [23].

\subsection{Fat necrosis/ organized hematoma}

Aspirates of fat necrosis/organized hematoma show inflammatory cells, hemosidrin laden macrophages, multinucleated cells with or without cholesterol crystals and a necrotic background [34]. Fat necrosis can also occur in combination with cancer. However, the fat necrosis will resolve with time, so a series of aspirates taken at monthly intervals can help in ruling out neoplasia.

\section{Conclusions}

\subsection{Best sample collection technique}

Among different cell retrieval techniques, tissue imprints or impression smear technique is found to be best followed by fine needle biopsy and teat discharge smears. The reason could be the fact that while making impression, the wider area of affected tissue came in contact with slide and thus enhanced obtaining of cellular material. Moreover the specimen can be easily collected from exact site of affected tissue (visible grossly) many a times without any difficulty like sudden movement of animal or bending of needle in hard tissue etc. However, obtaining of cellular material by means of fine needle aspiration combined with simultaneous preparation of tissue imprints is recommended.

\subsection{Limitations of cytology}

Inspite of expanding true positive cases of cytological testing, the diagnostic value of this method has many limitations. One of the major imperfections is "geographic miss" i.e. puncturing the lesion from inappropriate site and thus leading to misdiagnosis, so multiple aspirates by adequately trained hands are needed from multiple site of lesion in order to improve diagnostic value. Certain disadvantages of fine needle aspiration biopsy technique like sampling of low amount of tumor mass or inadequate tissue can be minimized by preparation of multiple aspirates from various areas of the lesion and the sampling should be performed from the peripheral areas instead of the center of the mass in which fluid and necrotic debris accumulate especially in big tumor formations [35]. Baker and lumsden 2000 [36] also encouraged preparation of more aspirates in order to increase the number of representative cells as cell types and tumor morphology differ beneath lesions.

The entry of blood in syringe while taking aspirate or entry of tissue fluid on pressing slide hard over the excised tissue while making touch impression contribute to contamination of smear and thus diminished diagnostic accuracy of cytology. In order to increase the 
precision of the cytological results, the application of "triple test" is recommended i.e., the combination of physical examination, imaging findings and the cytologic examination.

Cytological interpretation is most successful in slide preparations with one cell layer thickness and not broken. However, in such slides one can go to edge of smear for thin layer of cells. Artifacts like stain precipitates are commonly observed during smear examination as purple dots and mistaken for bacteria. To minimize the problem, stains should be changed weekly as many of the wright-giemsa stains favor fungal and bacterial growth also. Also, the precipitates are less observed in "dip" type stains like diff-quick stain.

Further, in cytologic preparations of hyperplasia and adenoma, differential diagnosis is very difficult and histological examination is required in consensus for accurate characterization and establishing medical prognosis or treatment.

However, as already shown by other studies in veterinary medicine, fine needle aspiration cytology had an edge over histopathological examination in terms of providing immediate diagnosis and thus timely determination of plan of action [37].

\subsection{Diagnostic value of cytology in mammary gland affections}

To conclude, cytology is most useful in diagnosis of neoplastic lesions followed by hyperplastic or inflammatory lesions. Even in cases in which diagnosis is not definitive, the fine needle aspiration features may guide the clinical and surgical management [38].

In case of inflammatory breast lesions, FNAC combined with microbiological studies can be helpful in identifying the causative agents and thus directs towards quick appropriate therapy. The presence of negative culture does not exclude infection; however, positive culture can direct therapy [28, 39]. In tune to this, workers like Das et al [39] and Nemenqani and Yaqoob [34] propagated fine needle aspiration technique to be useful in diagnosis of inflammatory breast lesions and their classification into acute mastitis/breast abscess, tuberculous mastitis, chronic non-specific mastitis and miscellaneous conditions.

Being non expensive and requiring minimal use of sophisticated instruments, we advocate the fine needle aspiration technique to be first hand choice for diagnosis in areas with economic constraints. Furthermore, the cytologic diagnosis is significantly associated with post operative patient outcome in univariate survival analysis [40].

Thus, the cytological interpretation is quiet helpful in rapid screening of the mammary gland affections, establishing diagnosis, identifying the pathogenesis, prognosis and directs towards what type of treatment should be opted in case of mammary gland affections.

\section{Author details}

Shivani Sangha* Incharge, Civil Veterinary Hospital Dakoha, Gurdaspur, Punjab, India

${ }^{*}$ Corresponding Author 
Amarjit Singh

Animal Disease Research Centre,

Guru Angad Dev Veterinary and Animal Sciences University, Ludhiana, Punjab, India

\section{Acknowledgement}

Authors are thankful to editor of Brazilian Jjournal of Veterinary Pathology for allowing to publish some of the pictures and data already published in the Brazilian Journal of Veterinary Pathology, 2011, 4 (1): 13-22, in the research paper entitled "Sensitivity and specificity of cytological techniques for the diagnosis of neoplastic and non neoplastic lesions of canine mammary gland".

\section{References}

[1] Shrestha A, Chalise S, Karki S, Shakya G. Fine needle aspiration cytology in a palpable breast lesion. Journal of Pathology of Nepal 2011; 1:131-135.

[2] Fausto KA. Robbins and Cortan Pathological basis of disease. Robbins, Cortan. (ed). $7^{\text {th }}$ edition, Elsevier. Philadelphia; 2004. p1121-1130.

[3] Karayannopoulou M, Kaldrymidou E, Constantinidis TC. Adjuvant post-operative chemotherapy in bitches with mammary cancer. Journal of Veterinary Medical Association Physiology Pathology Clinical Medicine 2001; 48:85-96.

[4] Anderson AC. Parameters of mammary gland tumors in ageing beagles. Journal of American Veterinary Medical Association 1965; 147:1653-1654.

[5] Fidler IJ, Abt DA, Brodey RS. The biological behavior of canine mammary neoplasia. Journal of American Veterinary Medical Association 1967; 151:1311-1318.

[6] Schneider R, Dorn CR, Taylor Don. Factors influencing canine mammary cancer development and post surgical survival. Journal of National Cancer Institute 1969; 43:1249-1261.

[7] Moulton JE. Tumors of mammary gland. In: Moulton JE. (ed.) Tumors in domestic animals. $3^{\text {rd }}$ edition. University of California press, Berkley and Los Angeles; 1990. p518-552.

[8] Hayes HMJR, Milne KL, Mandell CP. Epidemiological features of feline mammary carcinoma. Veterinary Record 1981; 108(22):476-479.

[9] Hayes AA, Mooney S. Feline mammary tumors. Journal of Veterinary Clinics of North America Small Animal Practice 1985; 15(3):513-520.

[10] Macewen EG. Spontaneous tumors in dogs and cats: Models for the study of cancer biology and treatment. Cancer Metastasis Review 1990; 9(2):125-136.

[11] Guthrie CJ. Gland puncture as a diagnostic measure. Bull Johns Hopkins Hospital 1921; 32:264-269.

[12] Engzell J, Jackobosan PA, Sigurson A, Zajicek J. Aspiration biopsy of metastatic carcinoma in lymph nodes of neck. Acta Otolaryngyol (Stockholm) 1971; 72:138-147. 
[13] Stockhaus C, Schoon HA, Grevel V, Oechtering G, Teske E. The diagnostic value of cytology in the diagnosis of soft tissue sarcoma in the dog and cat. Tieraztl prax 2003; 31:148-153.

[14] Stockhaus C, Teske E. Clinical experiences with cytology in the dog. Schweiz Arch Tierheilkd 2001; 143:233-240.

[15] Reinhardt S, Stockhaus C, Teske E, Rudolph R, Brunnberg L. Assessment of cytological crieteria for diagnosing osteosarcoma in dogs. Journal of Small Animal Practices 2005; 46:65-70.

[16] Hellmen E, Lindgren A. The accuracy of cytology in diagnosis and DNA analysis of canine mammary tumors. Journal of Comparative Pathology 1989; 101:443-450.

[17] Allen SW, Prasse KW, Mahaffey EA. Cytologic differentiation of benign from malignant canine mammary tumors. Veterinary Pathology 1986; 23:649-655.

[18] Misdrop W, Hart AA. Canine mammary cancer. I. Prognosis. Journal of Small Animal Practices 1979; 20:385-394.

[19] Rutterman GR. Mammary tumors in the dog. In: Kessler M (ed.) Small Animal Oncology. Berlin, Germany:Parey; 2000. p261-272

[20] Roglic M, Mouriquand J. Classification cytopronostique des tumeurs du sein. Senalogia 1980; 5:151-154.

[21] Wallgren A, Zajicek J. The prognostic value of the aspiration biopsy in mammary carcinoma. Acta Cytology 1976; 20:479-485.

[22] Verhaeghe M, Cornillot M, Herbeau J, Wintz A, Verhaeghe G. Le triplet diagnostic radioclinique dans les tumeurs due sein. A propos de 2460 cas. Memoire Academie Chirugi 1969; 95:48-61.

[23] Meinkoth JH, Cowell RL. Sample collection and preparation in cytology: Increasing diagnostic yield. Journal of Veterinary clinics small animal practice 2002; 32:1187-1207.

[24] Coles EH. Veterinary Clinical Pathology. $4^{\text {th }}$ edition. W.B. Saunders Company, Philadelphia, London; 1986.

[25] Abendroth CS, Wang HH, Ducatman BS. Comparative features of carcinoma in situ and atypical ductal hyperplasia of the breast on fine needle aspiration biopsy specimens. American Journal of Clinical Pathology 1991; 96:654-659.

[26] Sneige N, Staerkel GA, Caraway NP. A plea for uniform terminology and reporting of breast fine needle aspirates. The MD Anderson Cancer Center Proposal. Acta cytology 1994; 38:971-972.

[27] Masood S. Inflammatory breast lesions in Cytopathology of the breast. In: ASCP Theory and Practice of Cytopathology $5^{\text {th }}$ edition. USA ASCP Press Chicago; 1996. p51-76.

[28] Demay RM. Diseases and condition of the breast In: The Art and Science of Cytopathology: Aspiration Cytology. USA ASCP Press Chicago; 1996. p856-859.

[29] Tyler R, Cowell R, Tyler D, Baldwin C, Morton R. Introduction In: Cowell R, Tyler D, Meinkoth J, Mosby. (ed.) Diagnostic Cytology and Haematology of the Dog and Cat; 1999. p1-19.

[30] Alleman A, Bain P. Diagnosing neoplasia: The cytologic criteria for malignancy. Veterinary Medicine 2000; 3:204-222. 
[31] Mouriquand J, Fior MG, Villemain D, Bouchet Y, Sage JC, Mermet MA, Bolla M. Value of cytoprognostic classification in breast carcinomas. Journal of Clinical Pathology 1986; 39(5):489-496.

[32] Guidelines of the Papanicolaou Society of Cytopathology for Fine-Needle Aspiration Procedure and Reporting. Diagnostic Cytopathology 1997; 17(4):239-247.

[33] Mendoza P, Lacambra M, Tan PH, Tse GM. Fine needle aspiration cytology of the breast: The Non-malignant catagories. Journal of Pathology Research International 2011, Article ID 547580, p1-8.

[34] Dalal Nemenquani, Nausheen Yaqoob. Fine needle aspiration cytology of inflammatory breast lesions. Journal of Pakistan Medical Association 2009; 59(3):167-169.

[35] Henson K.L. Reproductive system. In: Raskin R, Meyer D.J (eds): Atlas of canine and feline cytology, W.B Saunders company, Philadelphia, 2001;277-289.

[36] Baker R, Lumsden JH. The mammary gland. In: Baker R, Lumsden JH (ed.) Color Atlas of Cytology of the Dog and Cat, Mosby, St Louis; 2000. p253-262.

[37] Larkin HA. Veterinary cytology fine needle aspiration masses or swellings on animals. Veterinary Journal 1994; 47:65-73.

[38] Haziroglu R, Yard B, Aslan S, Yildrim MZ, Yumusak N, Beceriklisoy H, Agaoglu R, Kucukaslan I. Cytological evaluation of canine mammary tumors with fine needle aspiration biopsy technique, Revue Medical Veterinary 2010; 161(5):212-218.

[39] Das DK, Sodhani P, Kashyap V, Parkash S, Pant JN, Bhatnagar P. Inflammatory lesions of the breast: Diagnosis by fine needle aspiration cytopathology 1992; 3:281-289.

[40] Simon D, Schoenrock D, Baumgartner W, Notle I, Barron R, Mischker. Cytological examination of fine needle aspirates from mammary gland tumors in dog: Diagnostic accuracy with comparison to histopathology and association with post operative outcome. Journal of Veterinary Clinical Pathology 2009; 38(4):521-528. 